\title{
Adopt, Adapt, Enact or Use?
}

\section{A Framework and Methodology for Extracting and Integrating Conceptual Mechanisms of IT Adoption and Use}

\author{
Jens Lauterbach ${ }^{1}$ and Benjamin Mueller ${ }^{2}$ \\ ${ }^{1}$ University of Mannheim, Chair of Information Systems IV, 68131 Mannheim, Germany \\ lauterbach@es. uni-mannheim.de \\ ${ }^{2}$ University of Groningen, Innovation Management \& Strategy Department, \\ 9747 AE Groningen, The Netherlands \\ b.mueller@rug.nl
}

\begin{abstract}
Information Systems (IS) are omnipresent in today's organizations. While much research has been performed on adoption, implementation, and use of IS, still many practitioners are faced with IS change endeavors in organizations that equal "death march" projects and fail before or directly after go-live. Research with a positivist stance has thoroughly studied factors that describe individuals' intentions to adopt or use technology, while largely ignoring social and organizational contexts. Researchers with a constructivist view, on the other hand, have studied how social processes and structures change or emerge in the light of the new IS. We suggest that there is a need to combine what we know from these two streams in an attempt to clarify terminological bafflement that seems to be caused by the different philosophical stances. Our paper contributes by suggesting a framework and methodology for collecting and reassembling scattered conceptual pieces of organizational and individual IT adoption and integrating them into a coherent understanding.
\end{abstract}

Keywords: IT adoption, information systems, change projects, IT use process, adaptation processes, business value, mechanisms, positivist stance, constructivist stance.

\section{Introduction}

Information technology (IT) and Information Systems (IS) are omnipresent and indispensable in today's world. Implementation of IS in organizations, such as ERP or CRM, promises a myriad of benefits in terms of standardization of technology-enabled value chains, creation of new business capabilities, efficiency gains, and increased productivity [1, 2]. Many change projects [3] that deal with the implementation of these Enterprise Systems (ES) ${ }^{1}$ and the complementary adjustments to the organization [4] and its work systems [5], however, never realize the intended benefits. As a

\footnotetext{
${ }^{1}$ In our paper, we address utilitarian IT and even if not explicitly mentioned in later parts of the paper our understanding fits very well to ES due their complexity, impact and importance for organizations.
} 
consequence, practitioners, such as managers or sponsors of these change endeavors, often find themselves in "death march" projects [6] that already fail to deliver prior to go-live [7-9]. Even if project management can claim success of releasing the new technology in time, scope, and budget, the chance to realize intended benefits often dies slowly after go-live; for example, due to organizational or individual resistance to adopt the new technology [10-12] or unintended use by some of the system's most important key users [13].

Thus, change projects for the introduction of new systems not only require managers' skills with regard to implementation, project, and change management to deliver expected project results. Their awareness and understanding of individuals' adoption, their responses to the new technology [14], and the emergence of actual IT use processes and dynamic patterns [15] seems equally important. Consequently, it has been suggested that these mechanisms play a vital role in the creation of organizational level benefits [15] or business value [16, 17]. Thus, understanding them is another step towards a better management of technology-related change projects that goes beyond traditional approaches and helps to fully leverage the potential of new technology to add real business value.

By looking at the extant literature, we identified two major streams that rely on a positivist or constructivist paradigm respectively. Both provide deep insights into understanding the phenomenon of technology adoption and use, but have also produced their own idiosyncratic terminology and concepts. Our goal is to reconcile these two camps by suggesting a way of how to resolve their conceptual tension. We argue that both streams do not provide two alternative views, but complementary perspectives on studying adoption and use and respective outcomes of IS in organizations.

With this paper, we want to contribute to building a shared conceptual and terminological foundation for complementing the "traditional" research on technology adoption and use. This can serve as a basis for further empirical investigations.

Our contribution will be to suggest a way of how concepts and terminology can be aligned on a common baseline and to provide an initial synthesis and discussion of our observations and knowledge from the positivist and constructivist paradigms. However, it seems important to highlight that this is a conceptual paper in which we propose a framework, methodology, and initial synthesis of terms and their understanding prevalent in the extant literature. As such, the paper is mainly focused on conceptual reasoning to help piece together the fragmented mosaic of technology adoption and use and advance our understanding (much like, e.g., Ramiller [18]). Others found that such an analysis is warranted as long as the results are dependable and consistent [19]. We suggest that it can inform future empirical research to fill the white spots on the research landscape of one of the most important research streams in the IS field [20].

The remainder of this paper is structured into four sections: The second section motivates the importance of IT adoption and use in the context of creating beneficial outcomes or value for organizations. It then gives a brief historical background on the two major IS research streams of IT adoption research, building on a positivist or constructivist stance respectively. Based on this knowledge, in section three, we suggest a methodology of how to synthesize and align our understanding on IT adoption 
and use. We then apply the methodology in two iterations by developing and refining an initial process-theoretical framework that incorporates processes, and mechanisms of organizational and individual IT adoption. In section four we conclude with a short summary and discussion of our limitations and contribution.

\section{Related Work}

\subsection{Why Study Adoption and Use of Technology in Organizations?}

Probably the most important reason why organizations decide to adopt IT in the first place and create "living" IS [21] is to gain benefits that help them sustain or achieve competitive advantage in their markets. However, many of them seem to struggle in this attempt: Many large change projects that deal with IS implementations have proven to be troublesome and have even led to high losses for the respective organizations [7-9, 22].

Soh and Markus [16] propose a process model that suggests a synthesis of how competitive advantage respectively business value is created from the adoption of IS. Soh and Markus' model shows "how, when, and why IT investment is converted to favorable organizational performance" [16, p. 39]. As an overall outcome, they argue that performance can only emerge if IT supports the business in the competitive process in the market. To do so, a company's business units need to be able to create IT impacts, that is, products and services in which IT is meaningfully embodied in a way that makes a difference in the market. This, in turn, is enabled by an appropriate use process of IT assets provided to the business units by the IT department. Finally, providing such assets is a result of the conversion process in which the IT department converts IT expenditure into assets. Only if a company exhibits the complete process embodying the conversion, use, and competitive processes will it be able to capture value from its IT expenditure [16]. In this model, the importance of time in the different processes and that intermediary results like IT assets are necessary in order to generate performance are major elements or ingredients of Soh and Markus' "recipe" that added explanatory power above and beyond existing models.

For our work, the model's explicit account of the use process as the central stage and necessary condition within the value creation sequence between the IT investment and the organizational performance is important. Since the introduction of the model, actual usage has been described as the "missing link" in the creation of beneficial outcomes for organizations [23].

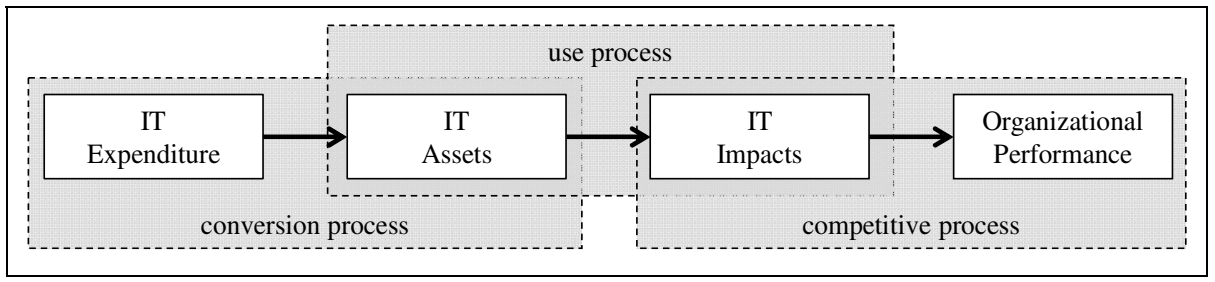

Fig. 1. IT business value process model [16] 
The importance of the use process has made research on use of IT one of the most intensively studied areas in the IS field [20]. To that end, research dealing with the organizations' and individuals' decision to adopt [24] and use IT in organizations has been focused to two main research streams that have each intensified and detailed what we know about adoption and use. Empirical research on individual adoption such as technology acceptance [25-27] or IS success [28, 29] - has shed light on individuals' intentions to adopt and use technology and its presumed individual and organizational outcomes [30]. Many studies in this area, most of which followed a positivist stance, have provided valuable and rich insights. Research has dealt with and conceptualized usage differently, for example IS success, IS acceptance, IS implementation, and IS for decision-making [8, 31]. Empirical studies in the tradition of IS success [29, 32], for example, specifically deal with the relationship between individuals' beliefs, intention to use or actual usage, and net benefits. Here, usage is treated as an independent or mediating variable leading to downstream impacts [31].

However, others suggest that studies in this "traditional" and "static" line of adoption research also have limitations. For example, the examination of the IT usage construct as snapshots of discrete elements [15] with predominantly variancetheoretical and quantitative methods only gives limited attention to the organizational context or the dynamics and emergent nature of technology adoption and its influence on the creation of organizational benefits [e.g., 8, 16, 33-36]. This suggests being particularly difficult when we look at change projects that necessarily take place within complex organizational contexts and are spread across time. As a response, researchers with a constructivist view - in a stream that we call "IT-induced organizational change" - rather understand technology as part of a complex process through which organizing is accomplished by focusing on dynamic interactions between technology and people over time [37]. They study the emergence of technology adoption with qualitative methods as a stream of social action in which people interact and respond to a technology's affordances and constraints [e.g., 4, 38]. But, in the attempt to overcome technological determinism, constructivist research is criticized for not sufficiently conceptualizing technology and for not differentiating between technologies [4]. This suggests being particularly difficult, when we want to understand the adoption and use of complex technologies such as ES. However, both these streams also seem limited to the view and terminology of their respective philosophical paradigm. Even though, this has produced in-depth and valuable insights, it has left us (e.g., researchers dealing with questions of value creation and practitioners in change projects) with no common guideline for identifying and performing empirical research as well as practical work. In order to help overcome this divide, the following two sections shortly discuss the historical evolution and basic paradigms of these streams on adoption and use of technology. This then serves as a basis for proposing an analytical synthesis of the two streams and the suggestion and example of how to build a common understanding necessary to conduct future work in research and practice. 


\subsection{Evolution of the Positivist Paradigm}

Work in this stream looks back at about four decades of research. Lucas et al. [30] describe this research stream as mainly focused on "implementation, innovation, and related themes." Table 1 provides a brief overview of this theme's historical evolution. For more thorough discussions, we point to Lucas et al. [30], Gallivan [24], Fichman [39], or Orlikowski [37] as well as the respective exemplary sources listed in Table 1.

Table 1. Historical development of positivist paradigm

\begin{tabular}{|l|l|l|}
\hline $\begin{array}{l}\text { Research Theme } \\
\begin{array}{l}\text { IT/IS implementation success and } \\
\text { failures }\end{array}\end{array}$ & $\begin{array}{l}\text { Timeframe } \\
\text { through 1980s }\end{array}$ & $\begin{array}{l}\text { Exemplary References } \\
\text { Swanson [42] }\end{array}$ \\
\hline $\begin{array}{l}\text { Innovation and its diffusion in the IT } \\
\text { context }\end{array}$ & $1980 \mathrm{~s}$ & Rogers [43, 44], Kwon and Zmud [45] \\
\hline $\begin{array}{l}\text { Individual adoption, acceptance and } \\
\text { usage of technology (IT innovations) }\end{array}$ & $\begin{array}{l}\text { late 1980s } \\
\text { through early } \\
1990 \mathrm{~s}\end{array}$ & $\begin{array}{l}\text { Ajzen and Fishbein [46], Davis [25], } \\
\text { Delone and McLean [28], Goodhue and } \\
\text { Thomson [32] }\end{array}$ \\
\hline $\begin{array}{l}\text { IT innovation diffusion and infusion } \\
\text { Assimilation of IT innovations }\end{array}$ & $\begin{array}{l}\text { 1990s } \\
\text { mid 1990s } \\
\text { through mid } \\
\text { 2000s }\end{array}$ & $\begin{array}{l}\text { Apple [48], Swanson [49], Kambil et al. } \\
\text { [50] }\end{array}$ \\
\hline $\begin{array}{l}\text { Fichman [39], Gallivan [24] } \\
\text { Responses to (disruptive) IT } \\
\text { innovations and richer } \\
\text { conceptualizations of usage behavior }\end{array}$ & $\begin{array}{l}\text { since early } \\
\text { 2000s }\end{array}$ & $\begin{array}{l}\text { Jasperson et al. [20], Beaudry and } \\
\text { Pinsonneault [14], Hsieh and Wang } \\
\text { [53], Elie-Dit-Cosaque and Straub [54], } \\
\text { Hsieh and Rai [55], Sykes et al. [56] }\end{array}$ \\
\hline
\end{tabular}

Research on IT implementation in the early 1970s dealt with problems that organizations face when introducing and implementing new IT and how they might be handled [30]. In a sense, the implementation process was seen as a bridge between design and utilization of a system. Until the early 1990s, many popular models were developed based on this work that addressed the issues of adoption, diffusion, or infusion of IT with structural and stage models on the individual or organizational level [45, 47]. Organizational research mainly focused on stage models [e.g., 51] as sub-type of process research models [24]. Rogers defined the first five-stage-model of innovation adoption and implementation in organizations, trying to unify the hitherto fragmented views. Other stage models of information technology innovation and diffusion followed in this line of research [e.g., 47, 57].

At the end of the 1980s, research on individual IT adoption and use started to be centered on theories and applications of theories from socio-psychological models to the IT context [58]. Among these are the theory of reasoned action [46], the diffusion of innovation theory2 [43, 44], the theory of planned behavior [59], the technology acceptance model [25], and task-technology-fit [32]. These models vary in their con-

\footnotetext{
2 Rogers' (1995) five-stage model of innovation differs from his model of individual adoption, the stages here are: knowledge, persuasion, decision, implementation, and confirmation.
} 
ceptual structures, constructs, and relationships. However, they all address the usage of technology [58]. What these models have in common is that they limit their view on predictors of individuals' beliefs and intentions to adopt and use an IT innovation.

Starting from the 1990s, we saw further diversification of research on innovation in the IT context that developed typologies for IT innovations [e.g., 49] and complemented concepts of diffusion with infusion, finally merging it under the umbrella of assimilation research. Important goals were to understand concepts of IT innovativeness and organizational learning processes and how the depth and breadth of organizations' use of technology alters processes, structures, and organizational culture $[52,60]$. Also attempts were made to create integrated models of individual and organizational adoption processes [24].

In the 2000s, research on adoption and use of technology in the positivist stream has become even more diverse with the intention to overcome early issues such as the lack of sufficiently rich technological, institutional, and historical conceptualizations and contexts. Working with and in real organizations, organizational level studies further analyzed the breadth and depth of IT innovation adoption. These were extended by mixed-level analyses as well as by context-rich and multiple methods [30]. This acknowledged that research ought to fully address the wide range of impacts of IT on multiple, complementary levels of analysis across individuals, organizations, and industries with the goal to better describe and explain IT-induced transformations [30]. In this line, criticism has been raised regarding the use of measures limited to behavioral intentions, self-reported use, and a lack of considering organizational dynamics [34]. Arguments have been made that usage as a construct is still rather weakly conceptualized and operationalized [61]. Others claim that usage is a behavior, appropriate for inclusion in a process model but not in a causal model, implicating that usage must precede impacts and benefits [62]. More recent research suggests that the traditional methodological focus on variance theoretical models, quantitative measures, and single levels of analysis [8, 16, 33] only shows one side of the coin. Dealing with the topic in a "greater IT Use leads to greater IT impacts" fashion seems not sufficient [16] and "increased use quantity does not necessarily imply increased individual or organizational benefit" [8, p. 1].

Thus, the "growing complexity of today's organizational IS has resulted in greater user discretion over how - as opposed to whether or how often - an IS is used" [8, p. 1]. Actions, choices, and cognitions of individuals are important elements of the use process $[20,55,63]$. Beyond the rather deterministic and static conceptualization of the relationship between intention to use, usage, and benefits, there is a growing awareness that organizational and individual dynamics (i.e., changes over time) need researchers' attention. It has been suggested that understanding these dynamics can help to further open the "black box of use" [14, 54, 64].

Despite these recent developments in this research stream, the underlying research paradigm can be summarized as depicted in Figure 2. Researchers largely assume that, given certain conditions, whenever X (independent variable) occurs, Y (dependent variable) will follow [65]. That is, quantities of facilitating and inhibiting factors will influence quantities of adoption (identified through joint variation), implementation and use, which in turn will determine quantities of certain outcomes [39]. This understanding is complemented by the idea that respective factors and outcomes can be examined for distinct stages of adoption and use. This empiricist stance is perhaps 
the dominant form of research in the positivist stream. It leads to studies that primarily focus on observation and measurement, classification, experiment, and statistical analysis. The results of such studies are intended to confirm or falsify pre-specified hypotheses about an objectively observable, independent reality [66].

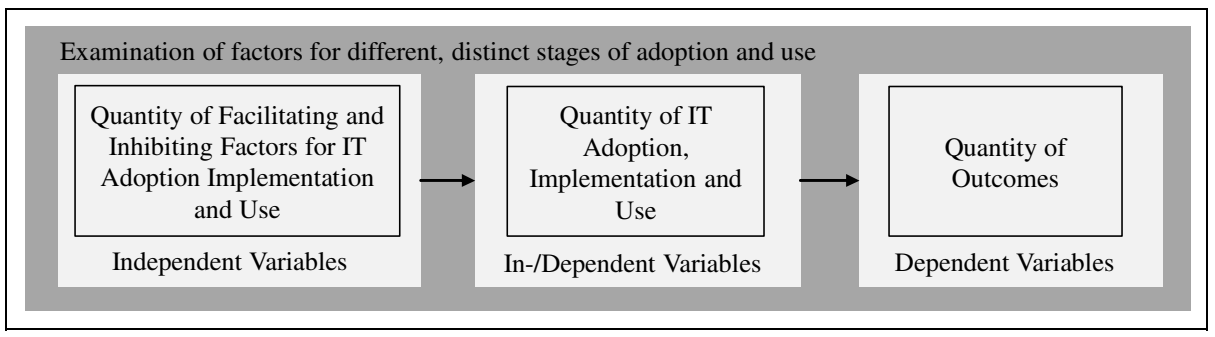

Fig. 2. Positivist research paradigm

\subsection{Evolution of the Constructivist Paradigm}

Comprehensive summaries of this research stream have just recently been provided by Leonardi and Barley [4] or Orlikowski and Scott [37]. They argue that researchers studying adoption and use of technology with this stance "generally hold that organizational change emerges from an ongoing stream of social action in which people respond to a technology's constraints and affordances, as well as to each other" [4, p. 1]. Table 2 provides a brief historical overview.

Table 2. Historical development of constructivist paradigm

\begin{tabular}{|l|l|l|}
\hline Research Theme & Timeframe & \multicolumn{1}{|l|}{ Exemplary References } \\
\hline $\begin{array}{l}\text { "Overcoming” technological } \\
\text { determinism }\end{array}$ & $\begin{array}{l}\text { Late 1980s or early } \\
1990 \mathrm{~s}\end{array}$ & $\begin{array}{l}\text { Barley [68], Orlikowski and Gash } \\
\text { [69], Markus [70] }\end{array}$ \\
\hline $\begin{array}{l}\text { Structures embedded in technology } \\
\text { shape social processes }\end{array}$ & Early 1990s & $\begin{array}{l}\text { Poole and DeSanctis [71], } \\
\text { DeSanctis and Poole [36], } \\
\text { Orlikowski [72] }\end{array}$ \\
\hline $\begin{array}{l}\text { Technologies in practice and } \\
\text { enactment and alignment shape social } \\
\text { processes and orders }\end{array}$ & $\begin{array}{l}\text { Mid 1990s till mid } \\
\text { 2000s }\end{array}$ & $\begin{array}{l}\text { Orlikowski [73], Boudreau and } \\
\text { Robey [74] }\end{array}$ \\
\hline $\begin{array}{l}\text { Sociomateriality and inseparability of } \\
\text { the material and social }\end{array}$ & Since mid 2000s & $\begin{array}{l}\text { Orlikowski and Scott [37], } \\
\text { Wagner and Newell [75], } \\
\text { Ramiller [18] }\end{array}$ \\
\hline Critical realist perspective & $\begin{array}{l}\text { Late 2000s, early } \\
\text { 2010s }\end{array}$ & $\begin{array}{l}\text { Volkoff et al. [76], Mutch [77], } \\
\text { Wynn and Williams [78] }\end{array}$ \\
\hline
\end{tabular}

Much of the constructivist research tradition we look at today is rooted in criticism towards early positivist studies. As these were often criticized for a technodeterminist view [79], early contributions following a constructivist paradigm aimed 
at overcoming the one-sided influence of technology on organizations and rather tried to understand organizational change as something that emerges from an ongoing stream of social action [e.g., 68].

Once foundations were laid out, research in this stream started to turn towards the structural properties of technologies and how they interact with established organizational structures. Thus, research posited that structure can be embedded or embodied in technology and individuals such as designers or managers define and shape these structures. Users in turn are influenced by these structures in their actions. Therefore, "once complete, the technology presents an array of social structures for use [...]" that as they are brought into interaction are instantiated in social life [36]. These interactions are defined as appropriations of the technology, that is, "immediate, visible actions that evidence deeper structuration processes" [36, p. 128]. Organizational change, in turn, emerges from social structuring processes that are formed by actors' appropriations of structures embedded in technology.

As a response, a contrasting stream of research soon highlighted that organizational change emerges from social structuring processes in which actors produce, reproduce, and change structures through ongoing situated action (recursive relationship between action and structure as in practice theory). This turn towards practices argued against structures embedded in technology and highlighted that what people do and what their doing so does matters most in our analysis of how technology shapes organizations. For example, Orlikowski [73] theorizes and proposes empirical examples for the introduction of Notes mail technology to different organizations where structuring processes (i.e., specific sets of rules and resources) are enacted in practice and serve to guide future technology use. Structures as "technologies-in-practice" then are integrated in other structures, relevant for guiding individuals' action in the organizational context [73].

However, this understanding seems limited in conceptualizing technology [ cf., 4]. More recently, then, the literature started turning towards sociomateriality in an attempt to equally emphasize both technology and structure. It assumes the existence of both material and human agency and suggests that they are interwoven in a way that one cannot exist without the other. They are "constitutively entangled in everyday life" [37, p. 1437], indicating that they only emerge and exist in relation to a practice they are both mangled into or imbricated with. While working with a sociomaterial ontology still seems challenging for many authors [79], the field has seen a number studies in this area. For example, Wagner and Newell [75] study how technological change leads to the need to renegotiate stable work practices across communities of practice. Introna and Hayes [80] or Lewis and Mathiassen [81] are other examples of how a sociomaterial stance is used to inform the study of IT-induced organizational change. They all highlight that, in addition to studying social processes, researchers need to pay attention to what a technology lets users do, what it does not let them do, and the workarounds they develop.

Complementary to sociomateriality, more and more attention seems to be dedicated to the potential role of critical realism. Both special sections in journals (e.g., Information and Organization's January issue in 2013) as well as conference workshops (AIS SIG-Philosophy workshop at ICIS 2013) are currently promoting the 
debate on the role of this stream of research for studies of technology adoption and use. In it, IT-induced organizational change is described by separation of structure and agency where pre-existing structures enable and constrain agency in social interaction to create new or reinforced structures. Despite its recency, this stream has already produced a number of interesting studies that illustrate its tenets [e.g., 76].

The above illustrates that the constructivist research stream has been equally active and prominent in studying adoption and use of IT. For a more elaborate discussion, we point to the articles mentioned in the introduction of this section. Summarizing the above, and to provide context for the analysis of the various concepts that emerge from the constructivist stream of research, Figure 3 depicts our understanding.

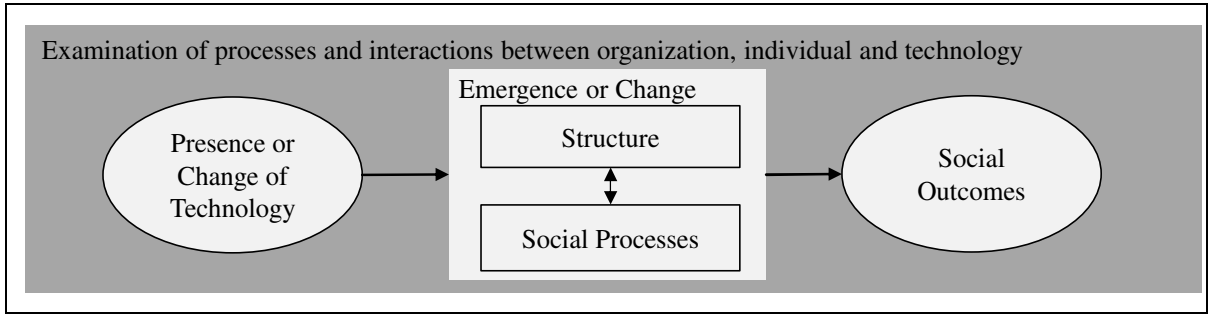

Fig. 3. Constructivist research paradigm

\section{Synthesis - Towards a Common Understanding}

The summaries of research in the positivist and constructivist paradigms mainly provide the historical context and a rough overview of the evolution of our understanding of the key phenomenon of IT adoption and use. Building on this foundation, we now turn towards our suggestion of how to reconcile the various terms that have been proposed across these two streams. In doing so, we first suggest a methodology and based on it develop a process-theoretical framework. We then show further examples of how to apply the methodology to iteratively refine the framework. Although we do not want to emphasize the philosophical discussion here, we admit our subjectivity while applying our methodology; however, we assume that the mechanisms we extract with it are part of an objective reality. This suggests closeness to the epistemological and ontological views of critical realism [77].

\subsection{Foundations and Methodology for a Conceptual Synthesis}

As indicated above, we suggest that the process model of how IT creates business value introduced by Soh and Markus [16] provides us with an important frame for our proposed analysis and synthesis. As suggested before it can serve as an overall motivation and frame i.e. a "true north" for the study of adoption and use of IT. Following this orientation, all the various terms the literature uses to describe adoption and use of technology should be analyzed in terms of their contribution to the creation of benefits or value for the organization. In this sense, our analysis aims 
at understanding how these terms relate to one another as necessary antecedents or preconditions for the overall emergence of benefits, such as competitive advantage, in the context of adopting and using IS in an organization. Following this assumption, our primary interest is in understanding the mechanisms of adoption and use (across both philosophical paradigms) that antecede beneficial outcomes or value, and how they relate to and build upon each other.

This understanding suggests that a process-theoretical stance lends itself as a basis for an integration of the various terms. For this, we see two main reasons. First, as indicated above, we are interested in fundamental mechanisms of adoption and use and their relations and suggest that business value as ultimate outcome (necessary but not sufficient) to be the adequate framework for studying them. This conceptual structure is an inherent property of process theories [82]. Second, our key focus is to better understand the conceptual and particularly temporal sequence of these mechanisms. Their focus on time, in turn, is a property of process theories that makes them a suitable lens for our work [83]. These meta-theoretical aspects [in the sense of 83] are complemented by the fact that we build on the model proposed by Soh and Markus [16] since their work also follows a process-theoretical stance.

While process theories are well defined and established in the IS literature [65, 83], we draw on Machamer [85] for a definition of mechanisms. Thus, mechanisms "are sought to explain how a phenomenon comes about or how some significant process works[; that is, they] are entities and activities organized such that they are productive of regular changes from start or set-up to finish or termination conditions" [85, p. 2]. Mechanisms are needed in many fields of science such as molecular biology to give satisfactory explanations of what holds the world together in its core.

Mechanisms are thus concepts that serve the purpose of explaining the reasons why a phenomenon emerges [66]. According to the definition they can be characterized by ending/termination conditions or outcomes, activities, that are performed by entities (such as the individual or groups or the organization or individuals' cognitions) and a starting point or starting conditions [85, p. 2].

With this conceptual foundation, we suggest that it is possible to go through the literature and build a conceptual map in which terms (i.e., mechanisms) can be put in relation to one another. This can be done based on the four characterizing questions for a mechanism depicted in Figure 4 that we derived from the definition of mechanisms suggested by Machamer [85].

This enables us to put concepts on a common ground and relate them to another, more specifically (1) some of the terms that are conceptually close enough can be blended into one overarching term and (2) or concepts can be mapped to each other in terms of their temporal or hierarchical (organizational vs. individual) sequence. This corresponds to our basic process-theoretical stance reported in this paper and allows for arrangement of mechanisms into phases/processes that have similar mechanisms within, and distinct mechanisms across. The methodology we are suggesting is iterative, thus, the resulting conceptual map is in flux, and might have to be revised as new concept is identified. This also applies to the framework that we present in the next paragraph which can be seen as a first step towards conceptual alignment. 


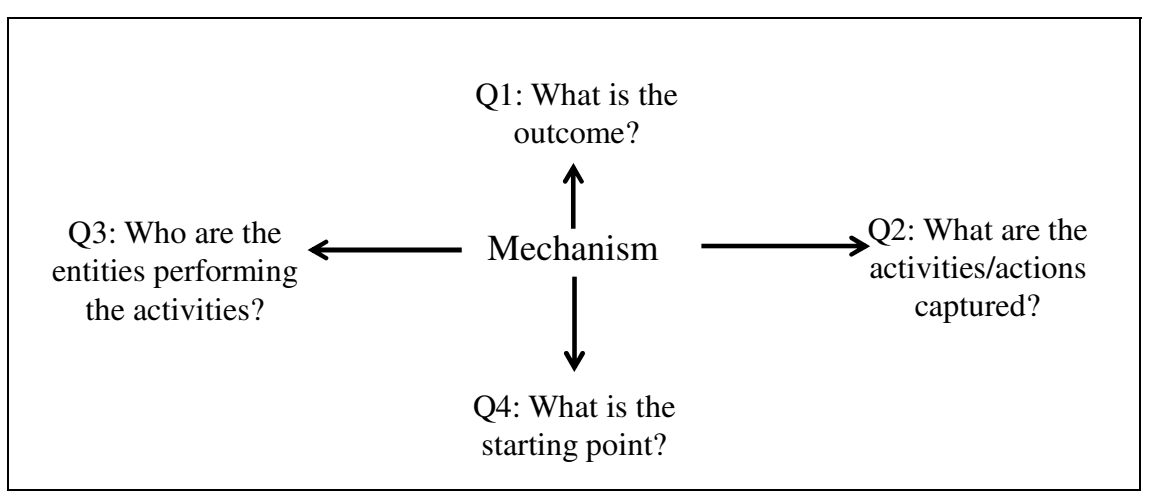

Fig. 4. Questions for characterizing mechanisms

For exemplifying our methodology and deriving our framework, we started a literature analysis with seminal papers and reviews in each of the research streams (such as, e.g., the JAIS 2007 special issue on TAM or the reviews by Orlikowski and Scott [37] and Leonardi and Barley [4]. Then we performed a backward and forward search based on the papers' references. We complemented this by selective database searches via Google Scholar. The mechanisms extracted in a thorough and careful analysis through selective coding [86] from each of the resultant papers were documented in an excel file. We then reviewed and discussed the descriptions and definitions and went back and forth between the original papers and our understanding of their terminology to produce an account of the mechanisms. Since the purpose of this paper is not to show a comprehensive account, but to demonstrate the ability of our approach to foster conceptual alignment, we will only provide and discuss an excerpt of the total mechanisms we extracted. ${ }^{3}$

\subsection{Towards a Comprehensive Process-Theoretical Framework}

To exemplify the suggested methodology in the last section, we derived a preliminary process-theoretical framework depicted in Figure 5 that we explain in the following. Processes in the framework are high-level representations of the mechanism concept (in italic in the following) that we have introduced above.

Using the model provided by Soh and Markus [16] as a starting point, we can assume that increased organizational performance leading to a competitive advantage for an organization is created in the competitive process that builds on impacts that are created in the IT use process. The use process involves all actions of individuals in an organization that deal with using and changing the technology or the respective work system to realize the intended impacts and business value. With work system, we refer to the organizational context in which individuals perform their work [20].

\footnotetext{
3 A table containing a more comprehensive account of mechanisms, their definitions, and a mapping to our preliminary framework can be provided by the authors on request. Taken altogether, our review identified 92 mechanisms across the positivist and constructivist stream.
} 
The use process as such has no defined end. However, it can be assumed that when we turn to the individual level of IT adoption, users need to appropriately use the technology [16]. In this structuring process of appropriations [36, 72] starting with what is often called initial usage, users, when they decide for continued usage [53, 87], run through several stages of individual usage (we used usage here to differentiate individuals' use from the organizational level use), ending with what is often called extension, a behavior where users explore and apply more of the technology's features in order to be able to handle a more comprehensive set of work tasks [88]. Extension occurs when users have already reached a stage of infusion, which is commonly defined as the IT application being deeply and comprehensively embedded within an individual's (or organization's) work system [60]. Infusion has routinization as a prerequisite, where the IT use is no longer perceived as out-ofordinary but becomes part of an individual's behavioral routine [88]. All these individual level mechanisms are often referred to as post-adoptive behavior [20].

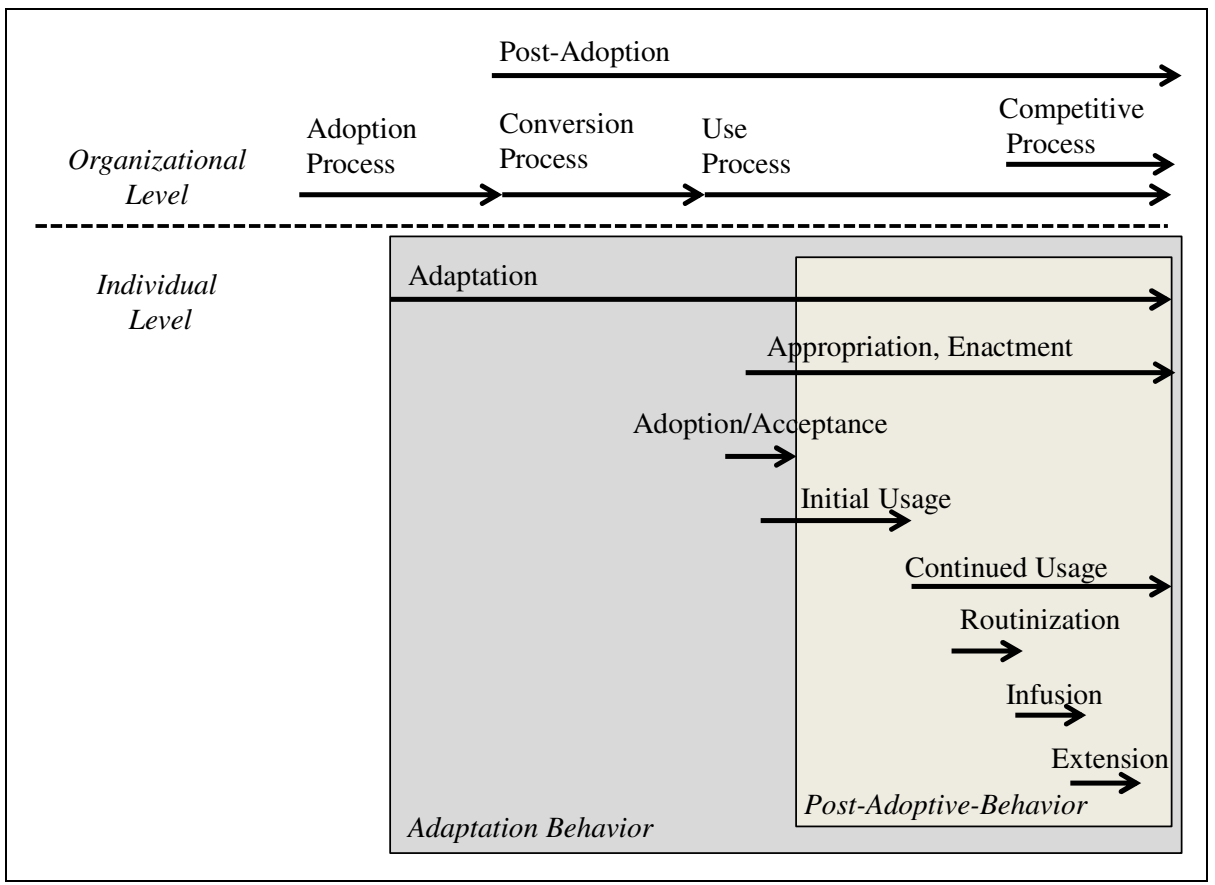

Fig. 5. Process framework of IT adoption and use

Before any of these mechanisms can commence, prospective users first need to make an adoption decision on whether they will use the new technology or not. The decision can be in the context of a mandatory adoption (e.g., ES adoption), where the organization forces the individual to use the technology, or it can be voluntary (e.g., use of an Enterprise Wiki). This decision is made some time after the adoption decision [20] of the organization in or latest at the end of the conversion process when the technology is released or rolled out to the organization and its users. Variations of 
technology acceptance cf. [cf., 89] have dealt with the cognitive processes (e.g., resulting in cognitions regarding a technology's usefulness and ease of use) associated with individuals' pre-adoption activities and the adoption decision.

We found some concepts in the literature for the individual level that start before actual adoption and acceptance of the individual takes place. For example user resistance [90]: it is often argued that resistance takes place during the use process, when users start interacting with the technology. However, we can also think of cases in which prospective users already resisted the technology by not supporting the respective implementation endeavors (e.g., lack of support for requirements analysis in the conversion process). Another example are coping mechanisms that users employ to handle the consequences of a technology event. Coping deals with acts that individuals perform in response to disruptive events that occur in their environment. These cognitive or behavioral efforts can already start before the technology has been delivered to the individual user [14]. To account for these concepts, we added the mechanism adaptation to our model. Concepts of adaptation referring to users responses to an IT event are often more generally defined as adaptation behavior [91].

From an organizational perspective the conversion process ends with the release or delivery of the IT assets to the host organization (i.e., business users as opposed to members of the IT department [49]). The conversion process involves all activities of individuals (in an organization or across organizations) that deal with developing and implementing the new technology. The IT department gets a business mandate to implement the technology; the outcome of the adoption process. From an organizational perspective, literature distinguishes the three-high level phases of pre-adoption, adoption, and post-adoption [92]. All activities of pre-adoption and adoption can be assigned to a generic adoption process that involves all actions of individuals in an organization that deal with creating awareness, selecting, evaluating, initiating, and deciding for the implementation of the new technology. This process ends with the adoption decision and allocation of resources performed by top managers of the host organization. The adoption decision refers to the evaluation of proposed ideas from technical, financial and strategic perspectives [92].

The process commences with the organizations' awareness of the IT innovation [93] or another trigger that drives IT-induced organizational change.

\subsection{Iterative Refinement of the Model by Applying Our Methodology}

As stated before, our iterative approach suggests that the proposed model is in flux and just a first step towards aligning our understanding on adoption and use between the two philosophical paradigms. For detailing our preliminary model, we further extracted and analyzed terms of adoption and use from the literature as mechanisms and tried to map them to the initially developed phases and/or refined the model. Due to space restrictions, we focus on a few examples (an explicit application of our methodology to several terms is visible in Table 3) to further show the applicability of our approach. We will focus on concepts that relate to the use process of our initial framework. 
After individual users have made their decision to adopt respectively accept, we find that the positivist research stream applies variations of the usage construct to describe how users employ or change the technology in actual usage to perform their work tasks. As opposed to cognitive mechanisms such as intentions to adopt or use a technology, here cognitive or behavioral mechanisms that rather want to capture initial or continued usage are important. For repeated usage conceptualizing interactions between the technology and the user over time are of essence [58], by describing technology as the independent variable or driving force. Here, researchers with a constructivist stance describe mechanisms such as patterns of use where not the technology is the independent variable. Rather the way how a group or individual adapts to a technology is the driving force in the causal effects of technology on human behavior and outcome [71]

We particularly found that the mechanisms that refer to the term adaptation in the two streams require explanation. Positivists recently started to use the term adaptive usage or adaptive system use behaviors to describe individual's behavior to selectively use and extend features offered by the technology [e.g., 94].

Others have also used the term to describe the more generic mechanism of user adaptation that can have several foci for example change the individuals' work system, the technology or the individuals' self - which constructivists refer to as appropriation - and from this understanding developed the idea that users can apply different adaptation strategies in response to the technology [14]. Kwon and Zmud [45] used adaptation to describe the process or phase in which an IT application is developed, installed, and maintained (in our model: conversion process).

When researchers with a constructivist view talk about users' adaptations in response to a technology they also describe it as enactment to emphasize human actions that create (enact) emergent structures through recurrent interaction with the technology at hand. These structures then guide future use and interaction with the technology in practice. In this structuring process users might come across periods of resistance where they try to work around certain functionalities that are then overcome by accommodations where individuals deeply deploy the technology in their everyday practice [75]. Then users will be able to use the technology for some parts of their practices up to its full potential (infusion) [88]. For other parts of their practices they still or engage in improvised learning [74]. Learning might then again lead to emergent [24] or unintended uses (also reinventions or unfaithful appropriations) of technology in workarounds that are negotiated as response to technology affordances and constraints $[36,75]$.

Taken together, these individual efforts in the organizational context, aim at achieving the goal to complete ones work or task with the technology. Research in the positivist stream has lately defined this as effective use [99]. 


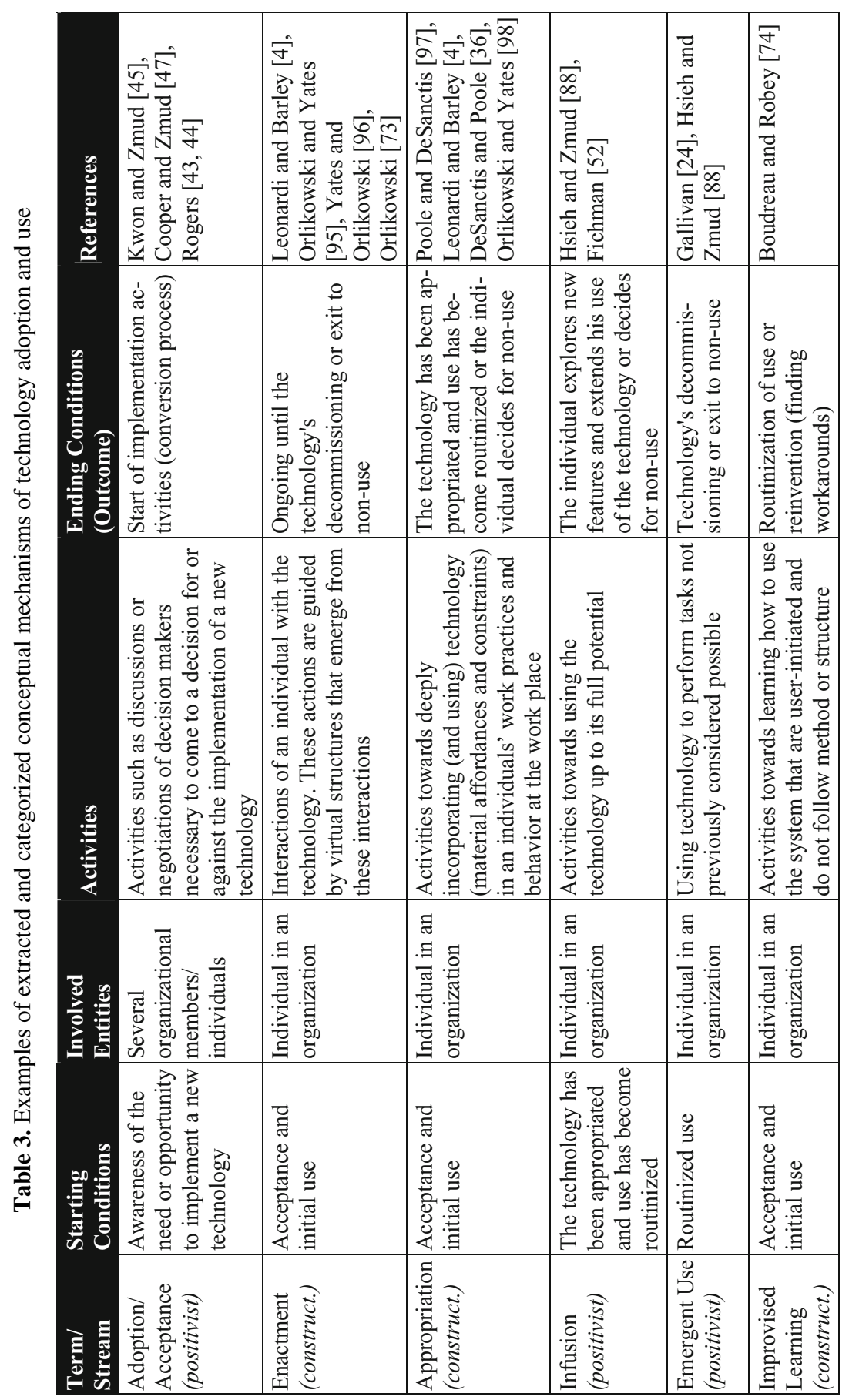




\section{Discussion and Conclusion}

As indicated earlier, the paragraphs above only scratch the surface of the discussion and analysis needed to integrate the knowledge from the two philosophical streams. However we wanted to show the need and applicability of our methodology for an integration of positivist and interpretive concepts used in the context of IT adoption and use. Taken altogether, for our review that consisted of two iterations of applying our methodology, we identified more than 90 mechanisms across the positivist and constructivist stream.

The application of our methodology and the resulting conceptual synthesis provides several contributions to research. First and foremost, our approach helps to integrate concepts into a comprehensive nomological net, that at first sight due to their entirely different philosophical foundations seem incommensurable. Here we want to emphasize that we do not attempt to reconcile the philosophical paradigms (which some might find neither possible nor desirable), but suggest a pragmatic approach of how to create a common ground for understanding IT adoption and use, by putting aside the philosophical differences and discussion. Second, we suggest the value creation framework brought forward by Soh and Markus [16] as valuable starting point for analyzing and integrating concepts of IT adoption and use. Third, we borrow the mechanism concept that has been recognized in other scientific disciplines [85] to use it as a meta-theoretical construct for reconciling terminology on IT adoption and use. Fourth, in a first iteration, we provide an initial process-theoretical framework and show in a second iteration how it can be enhanced by applying our methodology that is based on the mechanism concept. In the course of our analysis, we were able to provide a discussion (although limited due to the format of the paper) of concepts and terms on IT adoption and use. This enabled us for example to confirm our initial feeling that there are several concepts or terms used in the context of IT adoption and use (used relatively synonymously, e.g. emergent use and reinvention) to describe similar mechanisms or the same terms are used to describe completely different mechanisms (homonyms, e.g. adaptation as implementing the technology or as changes in individuals' behavior).

In sum, we were motivated by the terminological heterogeneity in the field that often troubled us in our ongoing research work in the context of IS implementation projects in several organizations. So, we tried to start building a common understanding across the two major streams of IT adoption and use that rely on a positivist and constructivist research paradigm respectively. As a frame we suggest the value creation process and the meta-theoretical construct of mechanism for integrating concepts of IT adoption and use.

We are aware that the rather conceptual and methodological nature of our paper deserves discussion. We propose a synthesis of terms and their understanding prevalent in the extant literature and are thus limited to conceptual reasoning. Therefore, we tried to thoroughly build our arguments and construct a solid understanding and history of the extant literature. We were committed to guide the reader through our own sensemaking process and tried to argue and convince why our analysis and synthesis are warranted. However, this paper is only able to provide a 
snapshot of our complete analysis, understanding, and results. Thus, we focused on showing the suitability and initial results stemming from the application of our suggested methodology.

Keeping these limitations in mind, we provide a contribution by starting a discussion on aligning our understanding on one of the critical phenomena of IS research. We developed a process-theoretical methodology and "meta model" of technology adoption and use in organizations and started to integrate scattered conceptual pieces and terms. Of course, the results we present might be interpreted quite differently by researchers from the paradigms we tapped into. This effect might even be compounded by the rising interest in other paradigms such as realist or pragmatist ones. Nonetheless, we believe that this analysis is not only warranted, but needed, and can be the starting point for future empirical work that, besides all philosophical differences and discussions, can focus on the core phenomenon: What do individuals in organizations actually (need to) do (when and how) to create value when adopting and using IS?

\section{References}

1. Brynjolfsson, E., Hitt, L.: Beyond Computation: Information Technology, Organizational Transformation and Business Performance. Journal of Economic Perspectives 14, 23-48 (2000)

2. Shang, S., Seddon, P.B.: Assessing and Managing the Benefits of Enterprise Systems: The Business Manager's Perspective. Information Systems Journal 12, 271-299 (2002)

3. Andersen, E.S.: Toward a Project Management Theory for Renewal Projects. Project Management Journal 37, 15-31 (2006)

4. Leonardi, P., Barley, S.: What's Under Construction Here? Social Action, Materiality and Power in Constructivist Studies of Technology and Organizing. Academy of Management Annals 4(1), 1-51 (2010)

5. Alter, S.: Work System Theory: Overview of Core Concepts, Extensions, and Challenges for the Future. Journal of the Association for Information Systems 14, 72-121 (2012)

6. Yourdon, E.: Death March. Prentice Hall Professional, New Jersey, NJ (2004)

7. Krotov, V., Ives, B.: ERP Implementation Gone Terribly Wrong: The Case of Natural Springs. Communications of the Association for Information Systems 28, 277-282 (2011)

8. Fadel, K.: User Adaptation and Infusion of Information Systems. Journal of Computer Information Systems 52, 1-10 (2012)

9. Bulkeley, W.M.: Technology (A Special Report): Working Together - When Things Go Wrong: FoxMeyer Drug Took a Huge High-Tech Gamble; It Didn't Work. Wall Street Journal, Eastern edn., R25 (November 18, 1996)

10. Burkhardt, M.E., Brass, D.J.: Changing Patterns or Patterns of Change: The Effects of a Change in Technology on Social Network Structure and Power. Administrative Science Quarterly 35, 104-127 (1990)

11. Johnston, W., Zablah, A., Bellenger, D.: Customer Relationship Management Implementation Gaps. Journal of Personal Selling and Sales Management 14, 279-295 (2005)

12. Wen, C., Remus, U., Mills, A.: Understanding and Addressing User Resistance to IS Implementation in a Lean Context. In: ECIS 2011 Proceedings, Paper 171 (2011), http://aisel.aisnet.org/ecis2011/171 
13. Bartis, E., Mitev, N.: A Multiple Narrative Approach to Information Systems Failure: A Successful System That Failed. European Journal of Information Systems 17, 112-124 (2008)

14. Beaudry, A., Pinsonneault, A.: Understanding User Responses to Information Technology: A Coping Model of User Adaptation. MIS Quarterly 29, 493-524 (2005)

15. Nan, N.: Capturing Bottom-Up Information Technology Use Processes: A Complex Adaptive Systems Model. MIS Quarterly 35, 505-532 (2011)

16. Soh, C., Markus, M.L.: How IT Creates Business Value: A Process Theory Synthesis. In: ICIS 1995 Proceedings, Paper 4 (1995), http: / / aisel . aisnet . org/icis1995/ 4

17. Devaraj, S., Kohli, R.: Performance Impacts Of Information Technology: Is Actual Usage The Missing Link? Management Science 49, 273-289 (2003)

18. Ramiller, N.C.: Reconsidering Resistance in the Post-Human Era. In: Proceedings of the 19th Americas Conference on Information Systems, Chicago (2013),

http: //aisel.aisnet.org/amcis2013/ISPhilosophy/GeneralPresen tations/3/

19. Lincoln, Y.S., Guba, E.G.: Naturalistic Inquiry. Sage, New York (1985)

20. Jasperson, J., Carter, P., Zmud, R.: A Comprehensive Conceptualization of Post-Adoptive Behaviors Associated With Information Technology Enabled Work Systems. MIS Quarterly 29, 525-557 (2005)

21. Paul, R.J.: Challenges to Information Systems: Time to Change. European Journal of Information Systems 16, 193-195 (2007)

22. Devadoss, P., Pan, S.: Enterprise Systems Use: Towards a Structurational Analysis of Enterprise Systems Induced Organizational Transformation. Communications of the Association for Information Systems 19, 351-385 (2007)

23. Kohli, R., Devaraj, S.: Measuring Information Technology Payoff: A Meta-Analysis of Structural Variables in Firm-Level Empirical Research. Information Systems Research 14, 127-145 (2003)

24. Gallivan, M.: Organizational Adoption and Assimilation of Complex Technological Innovations: Development and Application of A New Framework. Database for Advances in Information Systems 32, 51-85 (2001)

25. Davis, F.D.F.: Perceived Usefulness, Perceived Ease of Use, and User Acceptance of Information Technology. MIS Quarterly 13, 319-340 (1989)

26. Venkatesh, V., Davis, F.D.: A theoretical extension of the technology acceptance model: Four longitudinal field studies. Managemenet Science 46, 186-204 (2000)

27. Venkatesh, V., Bala, H.: Technology Acceptance Model 3 and a Research Agenda on Interventions. Decision Sciences 39, 273-315 (2008)

28. DeLone, W., McLean, E.: Information Systems Success: The Quest for the Dependent Variable. Information Systems Research 3, 60-95 (1992)

29. Delone, W.: The DeLone and McLean Model of Information Systems Success: A TenYear Update. Journal of Management Information Systems 19, 9-30 (2003)

30. Lucas, H.J., Swanson, E., Zmud, R.: Implementation, Innovation, and Related Themes Over the Years in Information Systems Research. Journal of the Association for Information Systems 8, 206-210 (2007)

31. Burton-Jones, A., Straub, D.W.: Reconceptualizing System Usage: An Approach and Empirical Test. Information Systems Research 17, 228-246 (2006)

32. Goodhue, D., Thompson, R.: Task-Technology Fit and Individual Performance. MIS Quarterly 19, 213-236 (1995) 
33. Pare, G., Bourdeau, S., Marsan, J., Nach, H., Shuraida, S.: Re-examining the Causal Structure of Information Technology Impact Research. European Journal of Information Systems 17, 403-416 (2008)

34. Legris, P., Ingham, J., Collerette, P.: Why Do People Use Information Technology? A Critical Review of the Technology Acceptance Model. Information \& Management 40, 191-204 (2003)

35. Orlikowski, W.J.: Improvising Organizational Transformation Over Time: A Situated Change Perspective. Information Systems Research 7, 63-92 (1996)

36. DeSanctis, G., Poole, M.: Capturing the Complexity in Advanced Technology Use: Adaptive Structuration Theory. Organization Science 5, 121-147 (1994)

37. Orlikowski, W., Scott, S.: Sociomateriality: Challenging the Separation of Technology, Work and Organization. Academy of Managemenet Annals 2, 433-474 (2008)

38. Orlikowski, W.: CASE Tools as Organizational Change: Investigating Incremental and Radical Changes in Systems Development. MIS Quarterly 17, 309-341 (1993)

39. Fichman, R.: Going Beyond the Dominant Paradigm for Information Technology Innovation Research: Emerging Concepts and Methods. Journal of the Association for Information Systems 5, 314-355 (2004)

40. Lucas, H.C.: Why Information Systems Fail. Columbia University Press, New York (1975)

41. Zmud, R.W., Cox, J.F.: The Implementation Process: A Change Approach. MIS Quarterly $3,35-43$ (1979)

42. Swanson, E.B.: Information System Implementation: Bridging the Gap Between Design and Utilization. Irwin, Homewood (1988)

43. Rogers, E.M.: Diffusion of Innovations, 3rd edn. Free Press, New York (1983)

44. Rogers, E.M.: Diffusion of Innovations, 4th edn. Free Press, New York (1995)

45. Kwon, T.H., Zmud, R.W.: Unifying the Fragmented Models of Information Systems Implementation'. In: Boland, R.J., Hirshheim, R.A. (eds.) Critical Issues in Information Systems Research, pp. 227-251. Wiley, NY (1987)

46. Ajzen, I., Fishbein, M.: Understanding Attitudes and Predicting Social Behaviour. Prentice-Hall, New Jersey (1980)

47. Cooper, R.B., Zmud, R.W.: Information Technology Implementation Research: A Technological Diffusion Approach. Management Science 36, 123-139 (1990)

48. Zmud, R.W., Apple, L.E.: Measuring Technology Incorporation/Infusion. Journal of Product Innovation Management 9, 148-155 (1992)

49. Swanson, E.: Information Systems Innovation Among Organizations. Management Science 40, 1069-1092 (1994)

50. Kambil, A., Kamis, A., Koufaris, M., Lucas Jr, H.C.: Influences on the Corporate Adoption of Web Technology. Communications of the ACM 43(11es), Article 9 (2000)

51. Prescott, M.B., Conger, S.A.: Information Technology Innovations: A Classification by IT Locus of Impact and Research Approach. Database for Advances in Information Systems 26(2/3), 20-41 (1995)

52. Fichman, R.: The Diffusion and Assimilation of Information Technology Innovations. In: Zmud, R.W. (ed.) Framing the Domains of IT Management: Projecting the Future Through the Past, pp. 105-127. Pinnaflex, Cincinatti (2000)

53. Hsieh, J.J.P.-A., Wang, W.: Explaining Employees' Extended Use of Complex Information Systems. European Journal of Information Systems 16, 216-227 (2007)

54. Elie-Dit-Cosaque, C.M., Straub, D.W.: Opening the Black Box of System Usage: User Adaptation to Disruptive IT. European Journal of Information Systems 20, 589-607 (2011) 
55. Hsieh, J.J.P.-A., Rai, A., Xu, S.X.: Extracting Business Value from IT: A Sensemaking Perspective of Post-Adoptive Use. Management Science 57, 2018-2039 (2011)

56. Sykes, T., Venkatesh, V., Gosain, S.: Model of Acceptance with Peer Support: A Social Network Perspective to Understand Employees' System Use. MIS Quarterly 33, 371-393 (2009)

57. Saga, V.L., Zmud, R.W.: The Nature and Determinants of IT Acceptance, Routinization, and Infusion. In: Levine, L. (ed.) Diffusion, Transfer and Implementation of Technology, pp. 67-86. Elsevier, Amsterdam (1994)

58. Chin, W.W., Marcolin, B.L.: The Future of Diffusion Research. Database for Advances in Information Systems 32(3), 7-12 (2001)

59. Ajzen, I.: From Intentions to Actions: A Theory of Planned Behavior. In: Kuhl, J., Beckmann, J. (eds.) Action Control From Cognition to Behavior, pp. 11-39. Springer, Berlin (1985)

60. Apple, L., Zmud, R.: Measuring Technology Infusion/Incorporation. Journal of Product Innovation Management 9, 148-155 (1992)

61. Barki, H., Titah, R., Boffo, C.: Information System Use-Related Activity: An Expanded Behavioral Conceptualization of Individual-Level Information System Use. Information Systems Research 18, 173-192 (2007)

62. Seddon, P.: A Respecification and Extension of the DeLone and McLean Model of IS Success. Information Systems Research 8, 240-253 (1997)

63. Jeyaraj, A., Sabherwal, R.: Adoption of Information Systems Innovations by Individuals: A Study of Processes Involving Contextual, Adopter, and Influencer Actions. Information and Organization 18, 205-234 (2008)

64. Lee, H., Sawyer, S.: Conceptualizing Time, Space And Computing for Work and Organizing. Time \& Society 19, 293-317 (2010)

65. Langley, A.: Strategies for Theorizing from Process Data. Academy of Management Review 24, 691-710 (1999)

66. Mingers, J.: Real-izing Information Systems: Critical Realism as an Underpinning Philosophy for Information Systems. Information and Organization 14, 87-103 (2004)

67. Van de Ven, A.: Running in Packs to Develop Knowledge-Intensive Technologies. MIS Quarterly 29, 365-378 (2005)

68. Barley, S.: Technology as an Occasion For Structuring: Evidence from Observations of CT Scanners and the Social Order of Radiology Departments. Administrative Science Quarterly 31, 78-108 (1986)

69. Orlikowski, W.J., Gash, D.C.: Technological Frames: Making Sense of Information Technology in Organizations. ACM Transactions on Information Systems 12, 174-207 (1994)

70. Markus, M.L.: Electronic Mail as the Medium of Managerial Choice. Organization Science 5, 502-527 (1994)

71. Poole, M.S., DeSanctis, G.: Use of Group Decision Support Systems as an Appropriation Process. In: Proceedings of the 22nd Hawaii International Conference on System Sciences (HICSS), pp. 149-157. IEEE (1989)

72. Orlikowski, W.J.: The Duality of Technology: Rethinking the Concept of Technology in Organizations. Organization Science 3, 398-427 (1992)

73. Orlikowski, W.: Using Technology and Constituting Structures: A Practice Lens for Studying Technology in Organizations. Organization Science 11, 404-428 (2000)

74. Boudreau, M.-C., Robey, D.: Enacting Integrated Information Technology: A Human Agency Perspective. Organization Science 16, 3-18 (2005) 
75. Wagner, E., Newell, S., Piccoli, G.: Understanding Project Survival in an ES Environment: A Sociomaterial Practice Perspective. Journal of the Association for Information Systems 11, 276-297 (2010)

76. Volkoff, O., Strong, D., Elmes, M.: Technological Embeddedness and Organizational Change. Organization Science 18, 832-848 (2007)

77. Mutch, A.: Actors and Networks or Agents and Structures: Towards a Realist View of Information Systems. Organization 9, 477-496 (2002)

78. Wynn, D., Williams, C.: Principles for Conducting Critical Realist Case Study Research in Information Systems. MIS Quarterly 36, 787-810 (2012)

79. Mueller, B., Raeth, P., Faraj, S., Kautz, K.: On the Methodological and Philosophical Challenges of Sociomaterial Theorizing: An Overview of Competing Conceptualizations. In: ICIS 2012 Proceedings (2012), http://aisel.aisnet.org/icis2012/ proceedings / Panels/3/

80. Introna, L.D., Hayes, N.: On Sociomaterial Imbrications: What Plagiarism Detection Systems Reveal and Why It Matters. Information and Organization 21, 107-122 (2011)

81. Lewis, M.O., Mathiassen, L., Rai, A.: Scalable Growth in IT-Enabled Service Provisioning: a Sensemaking Perspective. European Journal of Information Systems 20, 285-302 (2011)

82. Mohr, L.B.: Explaining Organizational Behavior: The Limits and Possibilities of Theory and Research. Proquest Info \& Learning, San Francisco (1982)

83. Markus, M., Robey, D.: Information Technology and Organizational Change: Causal Structure in Theory and Research. Management Science 34, 583-598 (1988)

84. Mueller, B., Urbach, N.: The Why, What, And How of Theories in IS Research. In: ICIS 2013 Proceedings (2013), http://aisel.aisnet.org/icis2013/proceedings/ ResearchMethods/8/

85. Machamer, P., Darden, L., Craver, C.: Thinking About Mechanisms. Philosophy of Science 67, 1-25 (2000)

86. Glaser, B.G., Strauss, A.L.: The Discovery of Grounded Theory: Strategies for Qualitative Research. Transaction Publishers, New Jersey (2008)

87. Bhattacherjee, A.: Understanding Information Systems Continuance: An ExpectationConfirmation Model. MIS Quarterly 25, 351-370 (2001)

88. Hsieh, J.J.P.-A., Zmud, R.: Understanding Post-Adoptive Usage Behaviors: A TwoDimensional View. DIGIT 2006 Proceedings, Paper 3 (2006),

http://aisel.aisnet.org/digit2006/3

89. Bradley, J.: If We Build It They Will Come? The Technology Acceptance Model. In: Dwivedi, Y.K., Wade, M.R., Schneberger, S.L. (eds.) Information Systems Theory: Explaining and Predicting Our Digital Society, vol. 1, pp. 19-36. Springer, New York (2012)

90. Lapointe, L., Rivard, S.: A Multilevel Model of Resistance to Information Technology Implementation. MIS Quarterly 29, 461-491 (2005)

91. Beaudry, A., Pinsonneault, A.: The Other Side of Acceptance: Studying the Direct and Indirect Effects of Emotions on Information Technology Use. MIS Quarterly 34, 689-710 (2010)

92. Damanpour, F., Schneider, M.: Phases of the Adoption of Innovation in Organizations: Effects of Environment, Organization and Top Managers. British Journal of Management 17, 215-236 (2006)

93. Fichman, R.R.G., Kemerer, C.C.F.: The Assimilation of Software Process Innovations: An Organizational Learning Perspective. Management Science 43, 1345-1363 (1997)

94. Sun, H.: Understanding User Revisions When Using Information System Features: Adaptive System Use and Triggers. MIS Quarterly 36, 453-478 (2012) 
95. Orlikowski, W., Yates, J.: Shaping Electronic Communication: The Metastructuring of Technology in the Context of Use. Organization Science 6, 423-444 (1995)

96. Yates, J., Orlikowski, W.J., Okamura, K.: Explicit and Implicit Structuring of Genres in Electronic Communication: Reinforcement and Change of Social Interaction. Organization Science 10, 83-103 (1999)

97. Poole, M.S., DeSanctis, G.: Understanding the Use of Group Decision Support Systems: The Theory of Adaptive Structuration. In: Fulk, J., Steinfield, C. (eds.) Organizations and Communication Technology, pp. 173-193. Sage, Thousand Oaks (1990)

98. Orlikowski, W., Yates, J.: Genre Repertoire: The of Structuring Communicative Practices in Organizations. Administrative Science Quarterly 39, 541-574 (1994)

99. Burton-Jones, A., Grange, C.: From Use to Effective Use: A Representation Theory Perspective. Information Systems Research 24, 632-658 (2013) 